\title{
Collaborative shipping under different cost-sharing agreements*
}

\author{
Silvia Valeria Padilla Tinoco, Stefan Creemers, Robert Boute ${ }^{\dagger}$ \\ May 4, 2017
}

\begin{abstract}
We study collaborative shipping where two shippers bundle their shipments to share the same transportation vehicle (also known as co-loading). The goal of such a collaboration is to reduce the total number of transports, thereby reducing transportation costs and $\mathrm{CO}_{2}$ emissions. To synchronize the replenishment of both companies, we adopt a can-order joint replenishment policy for both companies, and we analyze how the costs of each individual company are impacted by the collaboration. We consider different agreements to redistribute the costs (or the gains) of the collaboration, ranging from no cost redistribution at all, sharing the transportation costs (or its gains) only, to sharing the total logistics costs (or its gains) that are impacted by the collaboration, i.e., transportation + inventory costs. We show that the stability (and thus the long-term viability) of the partnership strongly depends on the cost-sharing agreement, in combination with the allocation mechanism used to share the costs (or gains) of the coordination. Although most companies focus on the redistribution of transportation costs, we show that this might not lead to a stable situation where each individual company eventually benefits from collaboration.

keywords: Supply Chain Management, Horizontal collaboration, Joint replenishment, Co-loading, Can-order policy, Gain sharing, Cost allocation
\end{abstract}

\section{Introduction}

Collaborations in the supply chain have proven to be a successful means to reduce logistics costs within one and the same supply chain (Goyal and Gupta, 1989). This type of vertical

*Accepted for publication in European Journal of Operational Research

${ }^{\dagger} \mathrm{KU}$ Leuven. Faculty of Economics and Business. Research Center for Operations Management 
supply chain collaborations are typically established between suppliers and buyers. Horizontal collaborations, on the other hand, are established between companies that operate at the same level in different supply chains, i.e., between suppliers or between buyers. Sharing transportation capacity when moving freight is an example of this type of horizontal collaboration, an option that benefits the environment and yields substantial network efficiencies (Saenz, 2012). Cruijssen et al. (2007a,b) review the literature on horizontal cooperation in transport and logistics and highlight its opportunities and impediments.

These horizontal collaborative shipping agreements are gaining attraction in today's business world. By bundling or co-loading transport shipments, the available space in transportation vehicles can be utilized more efficiently. A 2009 World Economic Forum report indicates that $24 \%$ of "goods vehicles kms" in the EU are running empty. When carrying a load, vehicles are typically loaded for only $57 \%$ of their maximum gross weight (Doherty and Hoyle, 2009). This problem of low utilization rates is getting worse. The total cost was estimated at $160 €$ billion in 2012, compared to $120 €$ billion in 2001 (Saenz, 2012). After optimizing internally, companies now look for opportunities beyond their own walls. That is why companies have started co-loading or bundling their shipments, by setting up partnerships with other shippers, whether or not they are direct competitors, with the objective to further reduce transportation costs and $\mathrm{CO}_{2}$ emissions. Vanovermeire et al. (2014) report on some recent (successful) horizontal logistics alliances.

A collaboration agreement is usually set up to maximize the gains of the partnership. However, in order to have a stable (i.e., successful and sustainable in the long term) collaboration, each company should be able to reduce its individual costs, otherwise there is no incentive to participate. This means that not only the total logistics cost of the coalition should be reduced, the individual performance of each company is equally important, compared to the stand-alone situation where there is no collaboration. Therefore, an agreement can be made to either redistribute the (joint) collaboration costs to each company according to a partition rule, or to allocate the gains of the collaboration among each participating company. A wide range of possible cost and/or gain sharing allocation mechanisms are available for this purpose. Besides the selected allocation mechanism, the companies also need to agree on which set of costs (or gains) will be redistributed. In most horizontal logistics alliances, the primary focus has always been on (gains and allocations of) the transportation costs. However, the synchronization of shipments also impacts each company's inventory holdings. To maximize the gains of collaborative shipping, the collaborating partners are required to be flexible: they have to replenish their inventories either sooner or later than originally planned in order to benefit from joint transport. It may thus occur that a company reduces its transportation costs at the expense of higher inventory levels. Therefore, one should 
look at the total logistics costs resulting from the collaboration, as both transportation and inventories are impacted by the collaboration.

In this article, we analyze each company's transportation and inventory cost performance when they set up a collaborative shipping agreement that maximizes the coalition gains (i.e., minimizes the total joint logistics costs). We consider four types of cost-sharing agreements:

1. Each company pays for its own transportation and inventory costs, and no costs or gains are redistributed. When company $i$ joins the transport organized by company $j$, then company $i$ does not pay for it; when company $j$ joins the transport of company $i$, company $j$ does not pay for it neither.

2. When multiple companies share space on the same vehicle (or any other transportation mode), they can decide to share the costs of the vehicles, which we denote as the major transportation costs. When the shipments do not have the exact same origin or destination, they may be consolidated using multi-stop truckloads. Under this agreement, each shipper pays for their own handling and minor transportation costs to accommodate for its individual pick-up and/or drop-off. Each company also pays for its own inventory holding costs.

3. Given that the benefits in joint major transportation costs are not possible without the multi-stop pick-ups, companies may agree to share and redistribute the total transportation costs, which is the sum of both major and minor transportation costs. Again, each company pays for its own inventory holding costs.

4. Finally, we consider the case where all logistics costs that are impacted by the coordination are redistributed. This means that both transportation as well as inventory holding costs are accounted for in the partnership, and either the total logistics costs or gains are redistributed among the participating companies.

The objective of this article is to investigate how the stability (and thus the long-term viability) of the collaborative shipping agreement is impacted by the cost-sharing agreement and the allocation mechanism used to share the costs or gains of the collaboration. We study a simplified setting with two companies. We assume that both companies sell a single item and the demand for each item follows an independent Poisson process. A canorder policy is used to synchronize the orders, and to enable joint replenishment of both companies. Assuming zero lead times, a Markov model is used to quantify the individual cost performance of transportation and inventory holdings under the can-order policy.

The article is structured as follows. Section 2 discusses the literature related to our work. Section 3 describes the analysis to quantify the transportation and inventory costs 
of each company when they adopt the can-order policy to synchronize orders, or when they operate independently. Section 4 discusses the cost-sharing agreements and the allocation mechanisms to distribute the costs or gains of the collaboration. Section 5 presents the results of an extensive computational experiment, and section 6 concludes.

\section{Related Literature}

In this article, we adopt a joint replenishment policy to synchronize orders of different shippers in a collaborative shipping agreement. The Joint Replenishment Problem (JRP) is a common problem in inventory-management literature, dealing with the synchronization of orders of different items within one and the same company. The goal of the JRP is to identify an order policy that minimizes inventory and ordering costs. The JRP usually assumes that there is a major and a minor order cost: the major cost is incurred each time an order is placed whereas the minor cost is incurred for each item that is added to the order. The JRP literature is rich: it can be divided into deterministic vs. stochastic models and periodic- vs. continuous-review models. We refer to Goyal and Satir (1989) and Khouja and Goyal (2008) for an overview of the JRP literature.

Ignall (1969) has shown that, even in a setting with zero lead times, the optimal JRP policy is not straightforward (e.g., the order quantity of one product can depend on the inventory level of another product). In this article, we focus on one particular class of JRP policies: the can-order policy. The can-order policy was first introduced by Balintfy (1964) and is a natural extension of the $(S, s)$ policy with a third parameter: the can-order level $c$. In Section 3 we describe the control mechanisms of the can-order policy in greater detail.

Although the control mechanism of the can-order policy is rather simple, the interaction between the products makes determining the optimal parameters difficult. Silver (1974, 1981), Thompstone and Silver (1975), Federgruen et al. (1984), and others suggest to decompose the $N$-item problem into $N$ single-item problems by representing the joint orders as "special discount opportunities" that incur a reduced set-up costs for all the other items after item $i$ has been ordered. As such, the discount opportunity for a given item is the superposition of the order processes of all other items. However, since the order decisions at one company depend on the inventory level of the other company, analyzing each company's inventory system separately results in a model that is no longer exact. The algorithm of Silver (1974) with Poisson demand and constant lead times is closest to our setting; however, their approach tends to overestimate the joint cost. The decomposition approach of Thompstone and Silver (1975), Silver (1981) and Federgruen et al. (1984) approximates the

number of joint orders by means of a Poisson process; Schultz and Johansen (1999) show 
(using simulation) that the Erlang-r distribution provides a better fit for the time between two joint orders - they find that in most cases, their approach outperforms the approach of Federgruen et al. (1984). However, it is evident that the number of joint orders of each company is not independent, which means that the decomposition approach will always remain an approximation.

In our article, we do not decompose the problem into two single-item inventory systems. We use a Markov chain with two dimensions instead of only one (i.e., for each additional item an extra dimension is required to keep track of its inventory level). This approach allows us to obtain exact cost figures. Our solution approach is closely related to the two-item models presented in Kayiş et al. (2008) and Timmer et al. (2013). Kayiş et al. (2008) model the two-item problem with positive lead times of equal length and an identical demand and cost structure (but different penalty costs for each company). Timmer et al. (2013) present a two-company coordination model where each company has an independent Poisson demand process and zero lead times. However, they do not include minor order costs, and consequently both companies always order jointly if one of the two reaches its respective reorder point (this policy coincides with a can-order policy where the can-order level equals the base-stock level). Their solution approximation is similar to Silver (1965). Our model copes with a more general fixed order cost structure and allows companies to have minor order costs as well as different cost and/or demand parameters; albeit with zero lead times.

The models in JRP literature are typically taken from the perspective of one company in a multi-item setting. Although several authors (e.g., Federgruen et al. (1984) and Kayiş et al. (2008)) state that a multi-item setting is equivalent to a multi-company setting, the practical difference is that in a multi-item setting, it is sufficient to analyze the cost reductions in total, rather than the cost reductions per individual item. Also, there is no need to redistribute the savings among the different items within the same company. This is different in a multicompany setting, where each company is interested in an individual cost reduction, and therefore the gains of the coordination need to be properly redistributed to each company in a fair and stable manner to ensure a long-term partnership. For this reason, Meca et al. (2004) have introduced inventory games to study mechanisms that share the joint costs resulting from inventory management under coordination. Most of the inventory game models treat demand as deterministic and exclude the minor order cost, which reduces the complexity of the problem, allowing it to be solved in polynomial time (Drechsel and Kimms, 2011). The research on inventory games that includes minor costs assumes a deterministic demand and solves the problem by means of a power-of-two policy (see for instance Federgruen and Zheng (1992), Anily and Haviv (2007), Dror and Hartman (2007), Zhang (2009), Fiestras-Janeiro et al. (2011), and Dror et al. (2012)). To the best of our knowledge, Timmer et al. (2013) 
has the only article that considers the allocation of joint costs under a stochastic demand. They study a two-company coordination where the companies have independent Poisson demand processes and zero lead times. However, they do not include minor order costs, and consequently, both companies always order jointly if one of them reaches its respective reorder point. Our approach allows for both stochastic demand and minor order cost. In case companies are not identical, the optimal number of orders placed jointly and/or individually is not the same for each company. This makes the decision on cost allocation less evident.

Once we have seen the cost savings resulting from collaboration, we deal with the problem of how to share the benefits of that collaboration among the different partners. This is not an easy question, since it is not obvious what the contribution of each company to the total cost savings is. Literature proposes many sharing mechanisms or cost allocations. Guajardo and Rönnqvist (2016) provide a recent overview of the cost-allocation methods found in the literature on collaborative transportation. Some are based on simple proportional rules, and others are based on theoretical concepts found in game theory. In contrast to game theoretical approaches, the former is more readily understandable and has more practical applications, because game theoretical concepts have a higher complexity. Certainly, one of the easiest approaches to allocate costs is the egalitarian method, which assigns equal cost shares to all the players. However, in this case, the input of each partner is ignored completely. A simple approach for cost allocation is to use a proportional ratio based on individual indicators of each partner in the collaboration; e.g., transportation volume, individual costs, etc. These concepts are working with activity measures.

A more advanced approach is to use principles based on cooperative game theory. The game theoretic gain sharing mechanisms go back to the bargaining problem defined by Nash (1950). Different methods based on game theory can be shown to have different theoretical properties. A frequently used allocation method is the so-called Shapley value (Shapley, 1953). The Shapley value and most of the better-known bargaining solutions in cooperative game theory of a two-player game all coincide with the "standard solution" (Nash, 1950; Aumann and Maschler, 1985). In words, the standard solution gives each player the amount that they can assure themselves, and divides the remainder equally between the two players. The standard solution makes sense, given that none of the gains can be achieved without both of the companies being present in the collaboration.

We contribute to the above stream of literature in the following ways: (1) we analyze the individual (transportation and inventory) cost performance when a can-order policy is adopted in a multi-company setting; (2) we analyze the redistribution of coordination costs and gains under different agreements, each characterized by a different set of costs to be allocated, and different cost-allocation mechanisms; (3) we evaluate when a collaborative 
shipping agreement is stable, and what allocation mechanism is to be used for each type of cost-sharing agreement.

\section{Inventory control model}

We study a single-item inventory model under continuous review, in which two companies (shippers), $N=\{1,2\}$, want to set up a collaborative shipping agreement to minimize logistics costs. Each company's demand is generated from an independent Poisson process with rate $\lambda_{i}>0$ for each $i \in N$. We assume zero lead times, which means that the inventory is replenished immediately after an order is placed. The companies are not allowed to run out of stock. As a result, there are no shortages or backlog.

We assume the following costs in our model. For each unit in inventory, company $i$ incurs a holding cost $h_{i}>0$ per unit of time. When a company $i$ initiates a replenishment order $Q_{i}^{s}$, it incurs a transport cost $K+k_{i}>0$ per replenishment, where $K$ is the major transport cost per replenishment (e.g., the transport cost of the truck or train to transport the goods) and $k_{i}$ the minor transport cost of this replenishment (e.g., the handling cost, or the cost of the last mile to reach company $i$ 's origin or destination). In this article, we use the terminology of major and minor transport cost, which corresponds to the major and minor order cost in JRP terminology. If company $j \neq i$ joins the order (and the transport) of company $i$ with order $Q_{j}^{c}$, it incurs only its minor transport cost $k_{j}$. Company $j$ may decide not to join company $i$ 's transport, for instance when it has sufficient inventory and does not want to pay the minor transport cost. In a second phase, the logistics costs can be redistributed among the companies, depending on the cost-sharing agreement, as will be discussed later.

\subsection{The stand-alone model}

To benchmark the cost performance under collaboration, we first analyze the cost performance when there is no horizontal collaboration, and each company operates independently (the stand-alone model). When there is no collaboration, the inventory dynamics of the companies are independent, and each company replenishes inventory following the $\left(Q_{i}, s_{i}\right)$ policy. When no shortages are allowed, the continuous-review, zero lead time setting follows the analysis presented in Silver (1974): the inventory is immediately replenished by an amount of $Q_{i}$, every time the inventory level is depleted to zero. In the remainder of this paper we will adopt this convention of setting $s_{i}=0$, although it is worth noting that the reorder point under the zero lead time assumption can be set to $s_{i}=-1$ because of instantaneous replenishment. 
A cycle is defined as the interval of time between two subsequent replenishments. With Poisson demand arrivals, the length of time in any state is exponentially distributed with mean $1 / \lambda_{i}$, and the time between orders follows an Erlang distribution with expectation $Q_{i} / \lambda_{i}$. Thus, the expected number of orders per unit time is defined as the inverse of the expected cycle length, which is given by $\lambda_{i} / Q_{i}$.

The inventory level process is a renewal process that regenerates every time an order is placed. The inventory position random variable has state space $\left\{1, \ldots, Q_{i}\right\}$. In steady state, the probability of visiting each of the inventory position states is uniformly distributed with probability $1 / Q_{i}$, and the expected inventory level of company $i$ equals $\left(Q_{i}+1\right) / 2$. The expected costs of company $i$ in the stand-alone model, $C_{i}^{n c}$ (the superscript $n c$ denoting no collaboration) are given by:

$$
\begin{aligned}
C_{i}^{n c} & =\left(K+k_{i}\right) \eta_{i}^{n c}+h_{i} \pi_{i}^{n c} \\
& =\left(K+k_{i}\right) \frac{\lambda_{i}}{Q_{i}}+h_{i} \frac{Q_{i}+1}{2}
\end{aligned}
$$

where $\eta_{i}^{n c}$ denotes the expected number of orders placed, and $\pi_{i}^{n c}$ is the expected inventory level of company $i$.

The optimal order quantity in the stand-alone policy that minimizes Eq. (1) is given by the square root solution $Q_{i}^{n c}=\sqrt{2 \lambda_{i}\left(K+k_{i}\right) / h_{i}}$, from which company $i$ will select the integer value that minimizes its expected cost rate $C_{i}^{n c}$ (note that when you plug in the square root solution into Eq.(1) and compute the minimum costs of the stand-alone solution, it is a lower bound of the best integer-valued solution). The total joint costs of the stand-alone model is then the sum of each company's stand-alone costs, or $C_{N}^{n c}=\sum_{i \in N} C_{i}^{n c}$.

\subsection{The collaborative model}

If both companies set up a collaborative shipping agreement to share the same transport, they need to adopt an inventory policy that synchronizes their replenishments. This can be done by installing a joint replenishment policy within both companies. A natural extension of the $\left(Q_{i}, s_{i}\right)$ policy is the can-order $\left(S_{i}, c_{i}, s_{i}\right)$ joint replenishment policy.

The can-order policy for firm $i$ is defined using three parameters $S_{i}>c_{i} \geq s_{i}$. Any order placed raises the inventory level up to its respective base-stock level $S_{i}$. The company that first reaches its reorder point is the one triggering the order - say it is $i$ : so inventory-onhand $I_{i}$ reaches its reorder point $s_{i}$ while $I_{j}>s_{j}$ for $j \neq i$. Then $i$ places an order of size $Q_{i}^{s}=S_{i}-s_{i}$ (we use superscript $s$ for "self-initiated" and $c$ for "collaborates"). The other company $j \neq i$ also replenishes (and joins the transport) if its inventory position $I_{j}$ is at 
or below its can-level $c_{j}$; if $I_{j}>c_{j}$, firm $j$ has sufficient stock and will not join the order. Hence, $Q_{j}^{c}=S_{j}-I_{j}$ if $I_{j} \leq c_{j}$ and $Q_{j}^{c}=0$ if $I_{j}>c_{j}$.

As discussed in our literature review, the can-order policy is a popular joint replenishment policy that has a simple coordinated control rule, and it is shown to perform well in many settings. Moreover, we see three additional benefits adopting the can-order policy in a collaborative shipping context. First, it allows placing joint orders, yet at the same time maintains the flexibility for each company to place an individual order even when the other company is not joining. Second, it allows for synchronization of orders without having to reveal explicit demand information to the other shippers. Finally, as the can-order policy has one additional degree of freedom compared to the $\left(Q_{i}, s_{i}\right)$ policy (if $c_{i}=s_{i}$, the can-order policy reduces to the $\left(Q_{i}, s_{i}\right)$ policy), the joint expected cost performance under collaboration will never be worse than in the stand-alone model.

Let $\eta_{i}^{s}$ denote the expected number of self-initiated orders of company $i$, and $\eta_{i}^{c}$ the expected number of orders that company $i$ joins company $j$ 's replenishment. As such, the expected costs of company $i$ under collaboration are given by:

$$
C_{i}\left(S_{i}, c_{i}, s_{i}\right)=K \eta_{i}^{s}+k_{i}\left(\eta_{i}^{s}+\eta_{i}^{c}\right)+h_{i} \pi_{i}
$$

and the total joint costs under collaboration is $C_{N}=\sum_{i \in N} C_{i}\left(S_{i}, c_{i}, s_{i}\right)$. The values of $S_{i}$ and $c_{i}$ (for zero lead times, we have $s_{i}=0$ ) are set to minimize the expected joint costs of the collaboration, $C_{N}$. In the next section, we show how the expected cost performance of company $i$ can be derived for a given set of parameters $\left(S_{i}, c_{i}\right)$. The optimal values of $\left(S_{i}, c_{i}\right)$ that minimize $C_{N}$ can then be found by an enumeration procedure.

The can-order policy may be implemented via a trustee (i.e., a central authority), who can keep track of company inventory levels to ensure that joint orders are placed. The trustee not only allows companies to keep their operating parameters private, but also makes sure that the expected cost for the whole system is optimized. In addition, the trustee also manages the allocation of the gains/costs in accordance with the selected allocation mechanism.

\subsection{Individual cost performance under a can-order policy}

We analyze the individual cost performance under collaboration by characterizing the replenishment cycle under a can-order policy by a Markov process. Let $\left(I_{1}, I_{2}\right)$ be the pair of inventory levels that represent the state of the system at a given moment in time. A new replenishment cycle starts at the base-stock level $S_{i}$ and a transition towards another state is made upon demand arrival (with rate $\lambda_{i}$ ). The time spent in each state is identically and exponentially distributed with rate parameter $\lambda_{N}=\left(\lambda_{1}+\lambda_{2}\right)$. The company that first reaches 
its reorder point $s_{i}$ initiates a replenishment order and makes a transition to its base-stock level $S_{i}$. If at that moment $I_{j} \leq c_{j}$ for company $j \neq i$, company $j$ also replenishes, and a transition is made to $\left(S_{1}, S_{2}\right)$. Table 1 summarizes the possible state transitions and Table 2 illustrates the infinitesimal generator $\mathbf{Z}$ of the Continuous-Time Markov Chain (CTMC), for $s_{1}=s_{2}=0, c_{1}=1, c_{2}=2, S_{1}=2$, and $S_{2}=4$.

Table 1: Summary of the possible state transitions in a can-order policy

\begin{tabular}{cll}
\hline \multicolumn{1}{c}{ Transition } & Transition Probability & \multicolumn{1}{c}{ Conditions } \\
\hline$\left(I_{1}, I_{2}\right) \rightarrow\left(I_{1}-1, I_{2}\right)$ & $\lambda_{1} \lambda_{N}^{-1}$ & $I_{1}>s_{1}+1$ \\
$\left(I_{1}, I_{2}\right) \rightarrow\left(I_{1}, I_{2}-1\right)$ & $\lambda_{2} \lambda_{N}^{-1}$ & $I_{2}>s_{2}+1$ \\
$\left(I_{1}, I_{2}\right) \rightarrow\left(S_{1}, I_{2}\right)$ & $\lambda_{1} \lambda_{N}^{-1}$ & $I_{1}=s_{1}+1 \wedge I_{2}>c_{2}$ \\
$\left(I_{1}, I_{2}\right) \rightarrow\left(S_{1}, S_{2}\right)$ & $\lambda_{1} \lambda_{N}^{-1}$ & $I_{1}=s_{1}+1 \wedge I_{2} \leq c_{2}$ \\
$\left(I_{1}, I_{2}\right) \rightarrow\left(I_{1}, S_{2}\right)$ & $\lambda_{2} \lambda_{N}^{-1}$ & $I_{2}=s_{2}+1 \wedge I_{1}>c_{1}$ \\
$\left(I_{1}, I_{2}\right) \rightarrow\left(S_{1}, S_{2}\right)$ & $\lambda_{2} \lambda_{N}^{-1}$ & $I_{2}=s_{2}+1 \wedge I_{1} \leq c_{1}$ \\
\hline
\end{tabular}

Table 2: Infinitesimal generator of a can-order policy with $s_{1}=s_{2}=0, c_{1}=1, c_{2}=2$, $S_{1}=2$ and $S_{2}=4$

\begin{tabular}{c|cccccccc}
$\left(I_{1}, I_{2}\right)$ & $(2,4)$ & $(1,4)$ & $(2,3)$ & $(1,3)$ & $(2,2)$ & $(1,2)$ & $(2,1)$ & $(1,1)$ \\
\hline$(2,4)$ & $-\lambda_{N}$ & $\lambda_{1}$ & $\lambda_{2}$ & 0 & 0 & 0 & 0 & 0 \\
$(1,4)$ & $\lambda_{1}$ & $-\lambda_{N}$ & 0 & $\lambda_{2}$ & 0 & 0 & 0 & 0 \\
$(2,3)$ & 0 & 0 & $-\lambda_{N}$ & $\lambda_{1}$ & $\lambda_{2}$ & 0 & 0 & 0 \\
$(1,3)$ & 0 & 0 & $\lambda_{1}$ & $-\lambda_{N}$ & 0 & $\lambda_{2}$ & 0 & 0 \\
$(2,2)$ & 0 & 0 & 0 & 0 & $-\lambda_{N}$ & $\lambda_{1}$ & $\lambda_{2}$ & 0 \\
$(1,2)$ & $\lambda_{1}$ & 0 & 0 & 0 & 0 & $-\lambda_{N}$ & 0 & $\lambda_{2}$ \\
$(2,1)$ & $\lambda_{2}$ & 0 & 0 & 0 & 0 & 0 & $-\lambda_{N}$ & $\lambda_{1}$ \\
$(1,1)$ & $\lambda_{N}$ & 0 & 0 & 0 & 0 & 0 & 0 & $-\lambda_{N}$
\end{tabular}

The infinitesimal generator $\mathbf{Z}$ has state-space dimension $S_{1} S_{2} \times S_{1} S_{2}$. Let $\mathbf{z}$ denote its steady-state distribution (satisfying $\mathbf{z Z}=\mathbf{0}$ with $\mathbf{z e}=1$, and $\mathbf{e}$ is a vector of ones). The expected inventory level of each company is then given by:

$$
\begin{aligned}
& \pi_{1}=\sum_{i=s_{1}+1}^{S_{1}} \sum_{j=s_{2}+1}^{S_{2}} i z(i, j), \\
& \pi_{2}=\sum_{i=s_{1}+1}^{S_{1}} \sum_{j=s_{2}+1}^{S_{2}} j z(i, j) .
\end{aligned}
$$

To determine each company's transportation costs, we need to know how often a company initiates and/or joins an order (resp. $\eta_{i}^{s}$ and $\eta_{i}^{c}$ ). Using the flow-rate-equation method (Tijms, 
2003), we find that:

$$
\begin{aligned}
\eta_{1}^{s} & =\sum_{I_{2}=1}^{S_{2}} \lambda_{1} z\left(1, I_{2}\right), & \eta_{1}^{c} & =\sum_{I_{1}=1}^{c_{1}} \lambda_{2} z\left(I_{1}, 1\right), \\
\eta_{2}^{s} & =\sum_{I_{1}=1}^{S_{1}} \lambda_{2} z\left(I_{1}, 1\right), & \eta_{2}^{c} & =\sum_{I_{2}=1}^{c_{2}} \lambda_{1} z\left(1, I_{2}\right) .
\end{aligned}
$$

Using Eqs. (3-4), we can determine the expected transportation and inventory cost performance of each individual company under collaboration when the can-order policy is used, as defined in Eq. (2).

The reason why we can obtain exact results is that the proposed Markov chain under two companies has $S_{1} \times S_{2}$ states. In case of three companies, the state space of our Markov chain increases to $S_{1} \times S_{2} \times S_{3}$. For large values of $S_{i}$, it becomes computationally intractable to determine the steady-state distribution of the Markov chain. For instance, if $S_{1}=S_{2}=$ $S_{3}=50$, the Markov chain has 125,000 states, and it is no longer possible to calculate the steady-state distribution. This is the reason why most researchers have resorted to the use of approximations to study systems that have more than 2 items, e.g. the decomposition approach. Given that current collaborative shipping practices are conducted with only two partners, we can use an exact solution approach.

There is no closed-form expression of the total cost function under a can-order policy with non-negative major and minor transport costs, even with zero lead times. Only when $K=0$ or $k_{i}=0$, it can be analytically shown that the cost function is convex in $S_{i}$ (when $K=0$, we have $c_{i}=s_{i}=0$, and the can-order policy reduces to the $(Q, s)$ policy, for which its cost function $C_{i}^{n c}$ is convex in $Q_{i}^{n c}$; when $k_{i}=0$, we have $c_{i}=S_{i}-1$ and both companies always place joint orders - Timmer et al. (2013) found that the cost function of this policy is convex). Our numerical results revealed that the cost function appears to be convex in $S_{i}$, and/or $c_{i}$. However, given that we are unable to prove the convexity of the cost function, we use a full enumeration procedure, rather than (faster) search methods that exploit the convexity of the cost function.

There are, however, some properties of the can-order policy, which will prove to be useful when analyzing the benefits of collaboration.

Proposition 1. If two companies establish a coordination using a can-order policy, their average order quantities will be lower or equal in the coordination than compared to the stand-alone policy.

Proof. We use a similar proof as in Timmer et al. (2013, Theorem 1). Without loss of generality, consider $i=1$. Assume that company 2 uses the same order quantity in coordination 
as in the stand-alone situation, i.e., $Q_{2}^{s}=Q_{2}^{n c}$. We distinguish between two possible scenarios in which company 1 places an order. In a first scenario, company 2 initiates the order and company 1 joins the order. In that case, company 1 has not reached its reorder level yet, meaning that it has some remaining cycle inventory from its previous order. In order to determine its optimal order quantity, company 1 will have to trade off its inventory costs against the minor transportation costs. Compared to the stand-alone case, company 1 has lower order costs and higher inventory holding costs (due to the remaining cycle inventory). Therefore, according to the same logic applied in the well-known EOQ formula, company 1 will order at most $Q_{1}^{n c}$ units. In a second scenario, company 1 initiates the order. In this case, it is optimal to order $Q_{1}^{n c}$ units. In both cases, company 1 orders at most $Q_{1}^{n c}$ units.

Proposition 2. If two companies establish a coordination using a can-order policy, the number of orders placed (self-initiated + joined) will be larger or equal in the coordination than compared to the stand-alone policy.

Proof. Because no shortages are allowed, the demand is satisfied in the stand-alone case by the total amount ordered: $\eta_{i}^{n c} Q_{i}^{n c}$. In the coordinated model, demand is fulfilled with self-initiated and joint orders: $\eta_{i}^{s} Q_{i}^{s}+\eta_{i}^{c} Q_{i}^{c}$. Then, by considering the "flow balance" of total demand, we have:

$$
\begin{aligned}
\eta_{i}^{s} Q_{i}^{s}+\eta_{i}^{c} Q_{i}^{c} & =\eta_{i}^{n c} Q_{i}^{n c} \\
\eta_{i}^{s} \frac{Q_{i}^{s}}{Q_{i}^{n c}}+\eta_{i}^{c} \frac{Q_{i}^{c}}{Q_{i}^{n c}} & =\eta_{i}^{n c}
\end{aligned}
$$

By design of the can-order policy with $s_{i} \leq c_{i}<S_{i}$, we have $Q_{i}^{c} \leq Q_{i}^{s}$. Then, in combination with Proposition 1, we have that $Q_{i}^{c} / Q_{i}^{n c} \leq Q_{i}^{s} / Q_{i}^{n c} \leq 1$, so that $\eta_{i}^{s}+\eta_{i}^{c} \geq \eta_{i}^{n c}$.

Proposition 3. If two companies establish a coordination using a can-order policy, the number of self-initiated orders for each individual company will be lower or equal in the coordination compared to the number of orders placed in the stand-alone policy.

Proof. Using the flow balance of total demand, we have that $\eta_{i}^{s} Q_{i}^{s}+\eta_{i}^{c} Q_{i}^{c}=\eta_{i}^{n c} Q_{i}^{n c}$. As $Q_{i}^{c} \geq 0$ and $\eta_{i}^{c} \geq 0$, we have:

$$
\begin{aligned}
\eta_{i}^{s} Q_{i}^{s} & \leq \eta_{i}^{n c} Q_{i}^{n c} \\
\eta_{i}^{s} \frac{Q_{i}^{s}}{Q_{i}^{n c}} & \leq \eta_{i}^{n c} .
\end{aligned}
$$

As $Q_{i}^{s} / Q_{i}^{n c} \leq 1$ (see Proposition 1 ), we find that $\eta_{i}^{s} \leq \eta_{i}^{n c}$. 


\section{Cost-sharing agreements}

We start with a description of the game theoretic concepts and then proceed with the description of the allocation rules. A cooperative game with Transferable Utilities (TU game) is a pair $(N, X)$ characterized by two main factors: $N=\{1,2, \ldots,|N|\}$ the given set of players, and $X$ the characteristic function. Every non-empty subset $U \subseteq N$ of cooperating players is called a coalition. $N$ is called the grand coalition. Further, the cost function $X: 2^{N} \rightarrow \mathbb{R}$ assigns to any non-empty coalition $U \subseteq N$ the minimal costs $X_{U}$ for the coalition if the individuals in $U$ cooperate without the players in $N \backslash U$. For the empty coalition, it assumes $X(\emptyset)=0$ and $X(\{i\})=X_{i}^{n c}$. The characteristic function can be interpreted as profits or costs. A cost game can be converted into a cost-savings game with $\nu\left(X_{U}\right)$ denoting the cost savings or gains in $X_{U}$, defined by:

$$
\nu\left(X_{U}\right)=\left(\sum_{i \in U} X_{i}^{n c}\right)-X_{U} \quad \text { for all } U \subseteq N .
$$

If $N=2$, there is only one possible form of cooperation, i.e., the grand coalition. Then, both players divide the coalition costs $X_{N}$ after some kind of bargaining process. In this article, we assume four different sets of costs $X_{N}$ that can be redistributed, defined in Section 4.1.

The allocation $\varphi_{i} \in \mathbb{R}$ denotes the share of the coalition costs $X_{N}$ that is allocated to player $i$. These shares should be computed in such a way that the vector $\varphi=\left(\varphi_{1}, \varphi_{2}, \ldots, \varphi_{|N|}\right)$ allocates the coalition costs $X_{N}$. We study allocation mechanisms based on simple proportional rules and based on game theoretical concepts in Section 4.2.

As only the set of costs $X_{N}$ is redistributed, we refer to the costs that are not allocated or redistributed under the agreement as "complementary costs". We denote $X_{i}^{\complement}=C_{i}-X_{i}$ the set of complementary costs of company $i$ under collaboration, and $X_{i}^{\complement, n c}=C_{i}^{n c}-X_{i}^{n c}$ the corresponding set of complementary costs of company $i$ in the stand-alone model. Hence, the total cost performance of company $i$ after allocation of $X_{N}$, which we denote by $\widetilde{C}_{i}$, is then given by:

$$
\widetilde{C}_{i}=\varphi_{i}+X_{i}^{\complement}
$$

\subsection{Redistribution of the costs and gains}

Collaboration has the objective to minimize the expected joint costs of both companies. The parameters of the can-order policy are thus optimized to minimize the total joint $\operatorname{costs} C_{N}=$ $\sum_{i \in N} C_{i}$, with $C_{i}$ the expected costs of company $i$ under collaboration, defined by Eq. (2). However, even when the partnership provides gains, i.e., $C_{N} \leq C_{N}^{n c}$, it is critical that each 
individual company $i$ has a lower cost performance in collaboration compared to its standalone performance. Only when $\widetilde{C}_{i} \leq C_{i}^{n c}$ there is an incentive for company $i$ to collaborate. Therefore, an agreement is made to redistribute (a part of) the joint costs of the collaboration, or to allocate (a part of) the collaboration gains to each company.

In most collaborative shipping partnerships, the focus is on allocating the gains in transportation costs. However, to maximize the gains in transportation costs, the collaborating partners are required to be flexible, and they have to replenish their inventories either sooner or later than originally planned in order to benefit from joint transport. This may come at the expense of increased inventories. As inventory costs are a sort of opportunity costs, they are not measurable in the same way as transportation costs because they are not of the same out-of-pocket character. In addition, they are often managed by a different department than the transportation department. Hence, when a collaborative partnership is discussed among transportation planners, its impact on inventories is often not taken into consideration, and the primary focus is on (gains and allocations of) the transportation costs. Nevertheless, although sharing inventory information may not be straightforward in practice, we will show next that when the inventory costs are not taken into account, some companies may end up thinking that they save costs, whereas actually they didn't.

We consider the following cost agreements to redistribute the set of costs $X_{N}=\sum_{i \in N} X_{i}$ between the participating companies:

1. In a first type of cost agreement, there is no redistribution of the costs:

$$
X_{N}=0 .
$$

This means that the company placing the order (and organizing the transport), pays for the transport, regardless of whether the other company joins or not. If the other company joins the order, it is only paying its minor transport cost.

2. Both companies share the payment of the (joint) major transportation costs:

$$
X_{N}=\sum_{i \in N} K \eta_{i}^{s}
$$

Under this agreement, each company still pays their own minor transport cost and inventory holding costs.

3. As the benefits in joint major transportation costs are not possible without multi-stop truckloads, companies may agree to share and redistribute the total transportation 
costs, which is the sum of both major and minor transportation costs:

$$
X_{N}=\sum_{i \in N}\left(K \eta_{i}^{s}+k_{i}\left(\eta_{i}^{s}+\eta_{i}^{c}\right)\right)
$$

In this case, the companies still pay for their own inventory costs.

4. Finally, companies may agree to share and redistribute all the logistics costs that are impacted by the collaborative shipping:

$$
X_{N}=C_{N}=\sum_{i \in N}\left(K \eta_{i}^{s}+k_{i}\left(\eta_{i}^{s}+\eta_{i}^{c}\right)+h_{i} \pi_{i}\right)
$$

Table 3 gives an overview of company $i$ 's set of costs $X_{i}$ that are redistributed under each agreement together with its set of complementary costs $X_{i}^{\complement}$, and its equivalent set of costs in the stand-alone model, $X_{i}^{n c}$ and $X_{i}^{\complement, n c}$.

Table 3: Set of costs under each agreement

\begin{tabular}{c|cc|cc} 
& $X_{i}^{n c}$ & $X_{i}^{\complement, n c}$ & $X_{i}$ & $X_{i}^{\complement}$ \\
\hline No redistribution & 0 & $C_{i}^{n c}$ & 0 & $C_{i}$ \\
Major transp & $K \eta_{i}^{n c}$ & $k_{i} \eta_{i}^{n c}+h_{i} \pi_{i}^{n c}$ & $K \eta_{i}^{s}$ & $k_{i}\left(\eta_{i}^{s}+\eta_{i}^{c}\right)+h_{i} \pi_{i}$ \\
Total transp & $\left(K+k_{i}\right) \eta_{i}^{n c}$ & $h_{i} \pi_{i}^{n c}$ & $K \eta_{i}^{s}+k_{i}\left(\eta_{i}^{s}+\eta_{i}^{c}\right)$ & $h_{i} \pi_{i}$ \\
Total logistics & $C_{i}^{n c}$ & 0 & $C_{i}$ & 0
\end{tabular}

We assume that each company provides its cost and demand information truthfully to a central authority. Arguably, under significant misreporting, the collaboration may suffer a substantial efficiency loss (we refer to Meca et al. (2003) and Körpeoğlu et al. (2012) who investigate the role of information in the context of a non-cooperative reporting game). In this article, we do not consider any information distortion. We assume that a neutral trustee manages the collaboration process as a central authority designed to facilitate information exchange and coordination efforts between companies (Gupta and Makowski, 2016).

\subsection{Allocation mechanisms of the costs/gains}

Once an agreement is made about which set of costs $X_{N}$ will be redistributed, the next question is which allocation rule will then be used to redistribute these joint costs $X_{N}$ to the partnering companies. In the literature, many sharing and cost allocation mechanisms have been proposed. Some are based on simple proportional rules whereas others are based on theoretical concepts found in game theory. A simple approach to allocate costs is to use 
a proportional allocation that can be based on individual indicators of each partner in the collaboration. A more advanced approach is to use principles based on game theory.

Proportional methods redistribute the set of joint costs $X_{N}$ to each company $i$ according to a proportional rule: $\varphi_{i}=\rho_{i} X_{N}$, where $\rho_{i}$ denotes the proportion of the costs allocated to company $i$. As only the set of costs $X_{N}$ are allocated, company $i$ additionally carries its complementary costs, $X_{i}^{\complement}$ (see Table 3 ). Hence, the total cost performance for company $i$ after allocation of $X_{N}$, is then given by:

$$
\begin{aligned}
\widetilde{C}_{i} & =X_{i}^{\complement}+\rho_{i} X_{N}, \\
& =C_{i}-\rho_{j} X_{i}+\rho_{i} X_{j} .
\end{aligned}
$$

In this article, we consider three proportional methods:

- Gerchak and Gupta (1991) propose to allocate the costs under a collaboration based on the ratio of each company's costs in the stand-alone model. We denote this rule the "Linear rule". The proportion of the costs $X_{N}$ that is allocated to company $i$ under the Linear rule, denoted by $\rho_{i}^{L}$, is then:

$$
\rho_{i}^{L}=\frac{X_{i}^{n c}}{\sum_{j \in N} X_{j}^{n c}} .
$$

The Linear rule is frequently used in the literature. The Linear rule coincides with the gain-sharing rule provided by Moriarity (1975), who allocates the gains $\nu\left(X_{N}\right)$, rather than the costs $X_{N}$, according to Eq. (12). It also coincides with the Equal Profit Method (Frisk et al., 2010), and the Weighted Relative Savings Model (Liu et al., 2010). In case of two identical companies, the cooperative gain-sharing mechanisms also reduce to the Linear rule, where half the gains or half of the costs is allocated to each company (Vanovermeire, 2014).

- Meca et al. (2004) introduce the distribution rule to allocate the (joint) major transportation costs to each company according to the ratio of each company's squared order frequencies in the stand-alone model $\left(\eta_{i}^{n c}\right)$. Even when each company pays for its own inventory costs, they show that this rule is stable, meaning that collaboration will always reduce each company's total (transportation + inventory) costs after allocation according to the distribution rule. Note that in their analysis, there is no minor transport cost. Whereas Meca et al. (2004) use this rule to distribute the major transportation costs only, we adopt the rule to distribute the costs $X_{N}$ (with $X_{N}$ depending on the type of agreement). We denote this rule the "Order rule", and denote $\rho_{i}^{\eta}$ the 
proportion of $X_{N}$ that is allocated to company $i$ under the Order rule:

$$
\rho_{i}^{\eta}=\frac{\left(\eta_{i}^{n c}\right)^{2}}{\sum_{j \in N}\left(\eta_{j}^{n c}\right)^{2}}
$$

- Finally, we extend the distribution rule to allocate the joint costs based on the ratio of its respective squared stand-alone $\operatorname{costs} X_{i}$. We denote this rule the "Square rule". Denote $\rho_{i}^{S}$ the proportion of the costs $X_{N}$ that is allocated to company $i$ under the Square rule:

$$
\rho_{i}^{S}=\frac{\left(X_{i}^{n c}\right)^{2}}{\sum_{j \in N}\left(X_{j}^{n c}\right)^{2}} .
$$

Under the agreement where only the major transportation costs are shared, the Square rule reduces to the Order rule.

Game theoretical concepts typically have a higher complexity. However, if only two companies participate in the collaboration, the cooperative game theory mechanisms all result in the same allocation, known as the standard solution (Aumann and Maschler, 1985), where the gains of the collaboration $\nu\left(X_{N}\right)$ are divided in two equal parts. If half of the gains in $X_{N}$ is allocated to company $i$, company $i$ 's costs are reduced from $X_{i}^{n c}$ to $X_{i}^{n c}-\frac{1}{2} \nu\left(X_{N}\right)$, and additionally, it carries its complementary costs $X_{i}^{\complement}$. Hence, the total cost performance for company $i$ after gain allocation is given by:

$$
\begin{aligned}
\widetilde{C}_{i} & =X_{i}^{\complement}+\left[X_{i}^{n c}-\frac{1}{2} \nu\left(X_{N}\right)\right], \\
& =C_{i}^{n c}-\nu\left(X_{i}^{\complement}\right)-\frac{1}{2} \nu\left(X_{N}\right),
\end{aligned}
$$

as $X_{i}^{n c}=C_{i}^{n c}-X_{i}^{\complement, n c}$, and $X_{i}^{\complement, n c}-X_{i}^{\complement}=\nu\left(X_{i}^{\complement}\right)$.

\subsection{Conditions for a successful collaboration agreement}

The set of costs $X_{N}$ considered in the collaboration agreement should be entirely distributed, or all gains in $X_{N}$ should be shared. In addition, to ensure a successful collaboration, the following three axioms must be satisfied after allocation of the costs/gains in $X_{N}$ :

Axiom 1. Subadditivity: The cost function $X$ is subadditive if:

$$
X\left(U_{1} \cup U_{2}\right) \leq X\left(U_{1}\right)+X\left(U_{2}\right) \text { for all } U_{1}, U_{2} \subseteq N \text { with } U_{1} \cap U_{2}=\emptyset
$$


A cooperative game is called concave if: $X\left(U_{1}\right)+X\left(U_{2}\right) \geq X\left(U_{1} \cup U_{2}\right)+X\left(U_{1} \cap U_{2}\right)$ for $U_{1}, U_{2} \subseteq N$. In a two-player game, $X(\emptyset)=0$, and the definition of concavity implies subadditivity as defined in Axiom 1. Also, in a two-player game the axiom of subadditivity reduces to $X_{N} \leq X_{i}^{n c}+X_{j}^{n c}$, or $\nu\left(X_{N}\right) \geq 0$. Clearly, if the property of subadditivity does not hold, there is no reason to cooperate.

Axiom 2. Core allocation: An allocation of the costs $X_{N}$ should be in the core of the game $\operatorname{Core}(N, X)$, which consists of those allocations of $X_{N}$ that satisfy:

$$
\operatorname{Core}(N, X)=\left\{\varphi \in \mathbb{R}^{N}: \sum_{i \in N} \varphi_{i}=X_{N} \text { and } \sum_{i \in U} \varphi_{i} \leq X_{U} \text { for all } U \subset N\right\}
$$

A core allocation $\varphi \in \operatorname{Core}(N, X)$ is efficient and it satisfies the individual rationality property with $U=\{i\}$, which is defined by $\varphi_{i} \leq X_{\{i\}}$ for all $i \in N$. If for two companies $X_{N}<X_{1}^{n c}+X_{2}^{n c}$, the two-company replenishment game is concave and the core

$$
\operatorname{Core}(N, X)=\left\{\varphi \in \mathbb{R}^{2}: \varphi_{1}+\varphi_{2}=X_{N}, \quad \varphi_{1} \leq X_{1}^{n c}, \quad \varphi_{2} \leq X_{2}^{n c}\right\}
$$

is a non-empty set.

We finally define the axiom of stability. In game theory terminology, the term "stable" refers to an element of the Core. However, given that the redistributed coalition costs $X_{N}$ do not necessarily coincide with the total coalition $\operatorname{costs} C_{N}$, we define stability as 'the condition where the cost performance in collaboration after redistribution of $X_{N}$ is better compared to the cost performance in stand-alone.'

Axiom 3. Stability: After allocation of the costs/gains, each company should be able to reduce its total cost performance:

$$
\widetilde{C}_{i} \leq C_{i}^{n c}
$$

Satisfying stability implies that the benefits are obtained at the level of the individual total cost performance, and not only the costs considered in the cost-sharing agreement. Hence, a given allocation mechanism may be individually rational for a given set of costs $X_{N}$, but not stable when the complementary losses outweigh the collaboration gains in $X_{N}$.

\section{Results}

Through an extensive numerical experiment for a range of cost and demand parameters we study the aforementioned allocation mechanisms and check if they belong to the core, meaning that its allocated costs are lower than its equivalent in the stand-alone model. For 
each type of cost-sharing agreement under the different allocation mechanisms, we also verify if stability is satisfied when the can-order policy is used to bundle orders, indicating whether its total logistics cost performance in collaboration (after allocation of the costs) is better than in the stand-alone model. In what follows, we first discuss the design of our experiment. In Section 5.2 we provide an illustrative example to understand the dynamics of the cost performance and the cost allocation under the different agreements, and in Section 5.3 we report on the results of the numerical experiment itself.

\subsection{Design of the experiment}

In our numerical experiment, we evaluate three different runs with varying combinations of major transport cost $K$, minor transport costs $k_{i}$, holding cost $h_{i}$, and different combinations of demand $\lambda_{i}$. Our parameters were selected similar to those used in the numerical tests in van Eijs (1994). Table 4 provides a detailed overview of the parameter values used. For each run we have $6(K) \times 5\left(k_{i}\right) \times 3\left(\lambda_{1}\right) \times 1\left(\lambda_{2}\right) \times 3\left(h_{1}\right) \times 3\left(h_{2}\right)=810$ instances, which gives a total of 2430 instances. However, in run 1 and 3, 162 identical instances are generated. We exclude these identical instances and report only on the $2268=2430-162$ instances.

Table 4: Experimental setup of the computational experiment

\begin{tabular}{c|cccccc} 
Run & $K$ & $k_{1}$ & $k_{2}$ & $\lambda_{1}$ & $\lambda_{2}$ & $h_{i}$ \\
\hline 1 & $\{0,25,50,75,100,125\}$ & $\{10,20,25,30,40\}$ & $50-k_{1}$ & $\{5,10,15\}$ & $\{15\}$ & $\{3,4,5\}$ \\
2 & $\{0,25,50,75,100,125\}$ & $\{5,10,12.5,15,20\}$ & $25-k_{1}$ & $\{5,10,15\}$ & $\{15\}$ & $\{3,4,5\}$ \\
3 & $\{0,25,50,75,100,125\}$ & $\{10,20,25,30,40\}$ & $k_{1}$ & $\{5,10,15\}$ & $\{15\}$ & $\{3,4,5\}$
\end{tabular}

\section{$5.2 \quad$ Illustrative example}

In Table 5 we illustrate for a specific setting the optimal inventory parameters for the standalone $\left(Q_{i}, s\right)$ policy and for the $\left(S_{i}, c_{i}, s_{i}\right)$ can-order policy under collaboration. Table 5 also reports on the respective expected inventory levels of each company $\left(\pi_{i}\right)$, the number of self-initiated orders $\left(\eta_{i}^{s}\right)$, and the number of joint orders $\left(\eta_{i}^{c}\right)$ under collaboration.

With the parameters reported in Table 5 we can quantify the cost performance of each company in the stand-alone scenario (using Eq. (1)) and in the collaborative setting (using Eq. (2)). For two specific $K$-values, Table 6 shows the major transportation costs (Major), the total (major + minor) transportation costs (Transp), and the total logistics (transportation + inventory) costs (Total). We can see that the resulting set of costs under collaboration for each company is smaller than the respective set of costs in their stand-alone operations. 
Table 5: Optimal inventory parameters for $k_{1}=10, k_{2}=40, h_{1}=5, h_{2}=3, \lambda_{1}=\lambda_{2}=15$

\begin{tabular}{c|cc|cccc|cccccc}
$K$ & $Q_{1}$ & $Q_{2}$ & $S_{1}$ & $c_{1}$ & $S_{2}$ & $c_{2}$ & $\pi_{1}$ & $\pi_{2}$ & $\eta_{1}^{s}$ & $\eta_{2}^{s}$ & $\eta_{1}^{c}$ & $\eta_{2}^{c}$ \\
\hline 0 & 8 & 20 & 8 & 0 & 20 & 0 & 4.5 & 10.5 & 1.875 & 0.750 & 0.000 & 0.000 \\
25 & 14 & 25 & 14 & 6 & 24 & 5 & 7.8 & 13.0 & 0.874 & 0.427 & 0.262 & 0.227 \\
50 & 19 & 30 & 19 & 13 & 22 & 9 & 10.7 & 12.6 & 0.545 & 0.344 & 0.333 & 0.433 \\
75 & 23 & 34 & 22 & 16 & 24 & 13 & 12.2 & 13.9 & 0.452 & 0.295 & 0.295 & 0.434 \\
100 & 26 & 37 & 24 & 19 & 26 & 15 & 13.3 & 15.0 & 0.414 & 0.268 & 0.268 & 0.405 \\
125 & 28 & 41 & 26 & 21 & 28 & 17 & 14.3 & 16.1 & 0.379 & 0.247 & 0.247 & 0.376
\end{tabular}

Table 6: Cost performance for $k_{1}=10, k_{2}=40, h_{1}=5, h_{2}=3, \lambda_{1}=\lambda_{2}=15$

\begin{tabular}{c|c|ccc|ccc}
\multicolumn{2}{l|}{} & \multicolumn{3}{c|}{ Company 1 } & \multicolumn{3}{c}{ Company 2 } \\
\hline & K & Major & Transp & Total & Major & Transp & Total \\
\hline \multirow{3}{*}{ Stand-alone $(Q, s)$} & 25 & 26.8 & 37.5 & 75.0 & 15 & 39 & 78.0 \\
& 125 & 67.0 & 72.3 & 144.8 & 45.7 & 60.4 & 123.4 \\
\hline \multirow{2}{*}{ Collaborative $(S, c, s)$} & 25 & 21.8 & 33.2 & 72.2 & 10.7 & 36.8 & 75.7 \\
& 125 & 47.4 & 53.6 & 125.1 & 30.9 & 55.9 & 104.0
\end{tabular}

We now analyze each company's cost performance after allocation of the costs $X_{N}$ according to the allocation rules described in Section 4.2. Table 7 shows the proportions $\rho_{i}$ of the costs allocated to company $i$ under the different cost agreements according to the Linear rule $(L)$, the Order rule $(\eta)$, and the Square rule $(S)$ using Eqs. (12-14). Table 7 also shows the resulting costs allocations $\varphi_{i}$ for these same rules and for the game theoretical approaches $\left(\varphi^{G}\right)$ using respectively Eq. (11) and (15). In this example, we find that all approaches are individually rational, except for the Order rule when the total transportation costs or the total logistics costs are shared. For instance, for $K=25$ the total logistics cost in stand-alone of company 1 equals 75 (see also Table 6), whereas if the Order rule is used to allocate the total logistics costs, the cost performance of company 1 in collaboration equals 112.6. As a result, this allocation method under this agreement fails the axiom of individual rationality and does not belong to the core.

Table 8 shows the total cost performance $\widetilde{C}_{i}$ after allocation of $X_{N}$, taking the complementary costs into account. We see that the Order rule fails to be stable under all cost agreements and the Square rule fails the axiom of stability when the major transportation costs are shared. Observe that for $K=25$ the Order rule is individually rational when the major transportation costs are shared, but it fails the axiom of stability as the total logistics cost for company 1 equals 75.1, which is slightly higher than in stand-alone. In this case, the reduction in major transportation costs are offset by the increase in minor order costs and inventory holding costs. 
Table 7: Proportions and allocated costs for $k_{1}=10, k_{2}=40, h_{1}=5, h_{2}=3, \lambda_{1}=\lambda_{2}=15$. * indicates that the allocation mechanism fails to be individually rational.

\begin{tabular}{c|c|ccc|ccc}
\multicolumn{2}{l|}{} & \multicolumn{3}{|c|}{ Company 1 } & \multicolumn{3}{c}{ Company 2 } \\
& K & Major & Transp & Total & Major & Transp & Total \\
\hline \multirow{2}{*}{$\rho^{L}$} & 25 & 0.641 & 0.490 & 0.490 & 0.359 & 0.510 & 0.510 \\
& 125 & 0.594 & 0.545 & 0.540 & 0.406 & 0.455 & 0.460 \\
\hline \multirow{2}{*}{$\rho^{\eta}$} & 25 & 0.761 & 0.761 & 0.761 & 0.239 & 0.239 & 0.239 \\
& 125 & 0.682 & 0.682 & 0.682 & 0.318 & 0.318 & 0.318 \\
\hline \multirow{2}{*}{$\rho^{S}$} & 25 & 0.761 & 0.480 & 0.480 & 0.239 & 0.520 & 0.520 \\
& 125 & 0.682 & 0.589 & 0.579 & 0.318 & 0.411 & 0.421 \\
\hline \multirow{2}{*}{$\varphi^{L}$} & 25 & 20.8 & 34.3 & 72.5 & 11.7 & 35.7 & 75.4 \\
& 125 & 46.5 & 59.7 & 123.7 & 31.8 & 49.8 & 105.4 \\
\hline \multirow{2}{*}{$\varphi^{\eta}$} & 25 & 24.7 & $53.3^{*}$ & $112.6^{*}$ & 7.8 & 16.7 & 35.3 \\
& 125 & 53.4 & $74.7^{*}$ & $156.3^{*}$ & 24.9 & 34.8 & 72.9 \\
\hline \multirow{2}{*}{$\varphi^{S}$} & 25 & 24.7 & 33.6 & 71.0 & 7.8 & 36.4 & 76.8 \\
& 125 & 53.4 & 64.5 & 132.8 & 24.9 & 45.0 & 96.4 \\
\hline \multirow{2}{*}{$\varphi^{G}$} & 25 & 22.1 & 34.3 & 72.4 & 10.4 & 35.8 & 75.4 \\
& 125 & 49.8 & 60.7 & 125.3 & 28.5 & 48.8 & 103.8
\end{tabular}

Table 8: Cost performance after allocation for $k_{1}=10, k_{2}=40, h_{1}=5, h_{2}=3, \lambda_{1}=\lambda_{2}=$ 15. *indicates that the cost performance under collaboration is higher than in stand-alone.

\begin{tabular}{c|c|ccc|ccc} 
& & \multicolumn{3}{|c|}{ Company 1 } & \multicolumn{3}{c}{ Company 2} \\
& $\mathrm{~K}$ & Major & Transp & Total & Major & Transp & Total \\
\hline \multirow{2}{*}{$\tilde{C}^{L}$} & 25 & 71.2 & 73.3 & 72.5 & 76.7 & 74.6 & 75.4 \\
& 125 & 124.3 & 131.1 & 123.7 & 104.9 & 98.0 & 105.4 \\
\hline \multirow{2}{*}{$\tilde{C}^{\eta}$} & 25 & $75.1^{*}$ & $92.3^{*}$ & $112.6^{*}$ & 72.8 & 55.6 & 35.3 \\
& 125 & 131.1 & $146.1^{*}$ & $156.3^{*}$ & 98.0 & 83.0 & 72.9 \\
\hline \multirow{2}{*}{$\tilde{C}^{S}$} & 25 & $75.1^{*}$ & 72.6 & 71.0 & 72.8 & 75.3 & 76.8 \\
& 125 & 131.1 & 136.0 & 132.8 & 98.0 & 93.1 & 96.4 \\
\hline \multirow{2}{*}{$\tilde{C}^{G}$} & 25 & 72.5 & 73.2 & 72.4 & 75.4 & 74.6 & 75.4 \\
& 125 & 127.5 & 132.2 & 125.3 & 101.6 & 96.9 & 103.8
\end{tabular}




\subsection{Computational experiment}

Table 9 reports for our entire numerical test set of 2268 instances the minimum and maximum relative gains of collaboration compared to the stand-alone case, measured by $\frac{\nu\left(X_{N}\right)}{X_{i}^{n c}} \times 100$. The higher the value of $K$, the higher the savings in the joint major transportation costs, the joint total transportation costs, and the joint total logistics costs (although not reported, the gains in joint inventory costs also increase for higher $K$-values).

Table 9: Percentage gains of the joint cost performance under collaboration

\begin{tabular}{|c|c|c|c|c|c|c|c|}
\hline \multirow[b]{2}{*}{$K$} & \multirow[b]{2}{*}{ Instances } & \multicolumn{2}{|c|}{$\begin{array}{c}\text { Major Transportation } \\
\text { Costs }\end{array}$} & \multicolumn{2}{|c|}{$\begin{array}{c}\text { Total Transportation } \\
\text { Costs }\end{array}$} & \multicolumn{2}{|c|}{$\begin{array}{c}\text { Total Logistics } \\
\text { Costs }\end{array}$} \\
\hline & & $\min$ & $\max$ & $\min$ & $\max$ & $\min$ & $\max$ \\
\hline 0 & 378 & 0 & 0 & 0 & 0 & 0 & 0 \\
\hline 25 & 378 & 10.79 & 34.72 & -1.27 & 17.95 & 1.38 & 9.20 \\
\hline 50 & 378 & 17.84 & 37.03 & 4.33 & 20.71 & 3.72 & 14.26 \\
\hline 75 & 378 & 16.21 & 36.85 & 5.41 & 22.75 & 5.63 & 16.65 \\
\hline 100 & 378 & 18.15 & 35.98 & 6.50 & 24.12 & 7.19 & 18.09 \\
\hline 125 & 378 & 22.75 & 34.14 & 12.66 & 24.44 & 8.70 & 19.06 \\
\hline
\end{tabular}

We find that the axiom of subadditivity always holds when the major transportation costs are shared, or when the total logistics costs are shared, indicating that under those agreements there are always gains in $X_{N}$. Indeed, following Proposition 3, the number of self-initiated transports for which a major transport cost is incurred is lower compared to the stand-alone model. Thus, when only the major transportation costs are shared, the set of gains $\nu\left(X_{N}\right)=K \sum_{i \in N}\left(\eta_{i}^{n c}-\eta_{i}^{s}\right)$ is always positive. Subadditivity is also satisfied when total logistics costs $X_{N}=C_{N}$ are shared, because the can-order policy has an additional degree of freedom compared to the stand-alone $(Q, s)$ policy, and as a result, the joint policy always performs better. The axiom of subadditivity is violated in 3 (out of 2268) instances when the total transportation costs are shared. More in-depth analysis reveals that this occurs when the ratio of major over minor transport costs is very low, in which case companies are most likely not even seeking any collaboration opportunities.

Furthermore, we find that the maximum gains are found in the joint major transportation costs. For instance, when $K=25$ the gains in joint major transportation costs range between $10.79 \%$ and $34.72 \%$. Hence, it is appealing to focus on these savings in the agreement, but in these cases, the complementary losses are also the largest. We found 129 (out of 2268) instances where the joint inventories increased under collaboration; the smaller the value of $K$, the higher the likelihood that inventories increase. In contrast, when the total logistics costs are shared, the gains may at first sight seem lower (e.g., for $K=25$ the gains 
range between $1.38 \%$ and $9.20 \%$ ), but in this case, there are no complementary losses (nor complementary gains).

When we analyze the individual cost performance of each company under collaboration prior to redistribution of the costs, $C_{i}$, we obtain similar results. In general, we find that:

- The major transportation costs for each company are always lower than in the standalone model. On the other hand, its minor transportation costs are always higher compared to the stand-alone model. The total (of major and minor) transportation costs may increase or decrease compared to its stand-alone performance, depending on the value of $K$ and $k_{i}$. The higher the major transport cost $K$, the higher the individual savings, and also the higher the likelihood that each company gains in total transportation costs.

- Each company's individual inventory costs may increase or decrease compared to the stand-alone model. Also here, the gains (and the likelihood of a positive gain) in inventory holding costs increase with larger values of $K$.

- The total logistics cost performance of each company will always improve in collaboration compared to the stand-alone model. The total cost savings will be higher for larger values of $K$.

These results can be explained by the dynamics of the can-order policy. Following Propositions 2-3, the number of self-initiated orders under collaboration is smaller than the number of orders placed in the stand-alone model $\left(\eta_{i}^{s} \leq \eta_{i}^{n c}\right)$, but the total number of replenishment orders increases compared to the stand-alone model $\left(\eta_{i}^{s}+\eta_{i}^{c} \geq \eta_{i}^{n c}\right)$. This explains the increase in minor transportation costs (and a potential increase in total transportation costs) under collaboration. The impact of the can-order policy on inventories is two-fold: on the one hand, decreasing order quantities result in lower base-stock levels and hence a decrease in cycle inventories. However, if $c_{i} \geq s_{i}$, the probability of having inventory levels lower than $c_{i}$, decreases, and the inventory distribution is no longer uniform over $I_{i} \in\left[s_{i}, c_{i}[\right.$, leading to average inventory levels higher than $\frac{S_{i}-s_{i}+1}{2}$. As a result, the impact of the can-order policy on inventory is a mixed effect and can be both positive or negative.

Table 10 reports how many times an allocation mechanism fails to be in the core of the game for the 2268 instances in our numerical experiment. For each of the cost-sharing agreements, we report how often the allocated costs $\varphi_{i}$ to company $i$ is higher than its comparable stand-alone performance $X_{i}^{n c}$. We denote these results in Table 10 as $\left[\begin{array}{ll}x_{1} & x_{2}\end{array}\right]$ with $x_{1}$ the results for company 1 and $x_{2}$ the results for company 2 . In general, we find that not only the game theoretic gain-sharing mechanisms (which satisfy individual rationality by 
definition), but also the Linear rule belong to the core of the game in all test instances. When the major transportation costs are shared, the Order rule (which is in that case identical to the Square rule), fails to be in the core of the game in 16 out of 2268 instances tested. More specifically, we find that this coincides with the instances where the demands of both companies are not identical. In addition, we see that, the larger the discrepancy between both companies, the more likely that Axiom 2 fails. When more costs are shared (i.e., including minor and/or inventory costs), we find that both the Order rule and the Square rule fail to provide a core solution more often, both for identical and non-identical demands.

Table 10: Number of times an allocation mechanism fails to be in the core of the game

\begin{tabular}{c|cccc} 
Cost-sharing agreement $X_{N}$ & Game theory $(G)$ & Linear rule $(L)$ & Order rule $(\eta)$ & Square rule $(S)$ \\
\hline Major transportation costs & {$\left[\begin{array}{ll}0 & 0\end{array}\right]$} & {$\left[\begin{array}{ll}0 & 0\end{array}\right]$} & {$\left[\begin{array}{ll}0 & 16\end{array}\right]$} & {$\left[\begin{array}{ll}0 & 16\end{array}\right]$} \\
Total transportation costs & {$\left[\begin{array}{ll}0 & 0\end{array}\right]$} & {$\left[\begin{array}{ll}0 & 0\end{array}\right]$} & {$\left[\begin{array}{lll}234 & 773\end{array}\right]$} & {$\left[\begin{array}{lll}125 & 748\end{array}\right]$} \\
Total logistics costs & {$\left[\begin{array}{ll}0 & 0\end{array}\right]$} & {$\left[\begin{array}{ll}0 & 0\end{array}\right]$} & {$\left[\begin{array}{lll}277 & 1041\end{array}\right]$} & {$\left[\begin{array}{lll}160 & 1029\end{array}\right]$}
\end{tabular}

We finally evaluate each company's total logistics cost performance, $\widetilde{C}_{i}$, under collaboration after allocation of the costs/gains in $X_{N}$ and compare it to its stand-alone costs, $C_{i}^{n c}$. Only when $\widetilde{C}_{i} \leq C_{i}^{n c}$, the collaboration is stable. Recall that the total costs of company $i$ include the allocated costs $\varphi_{i}$, as well as its complementary costs $X_{i}^{\complement}$. Hence, a collaboration may be individually rational but not stable when the losses in $X_{i}^{\complement}$ outweigh the gains in $X_{N}$.

Table 11 reports for the 2268 instances of our numerical experiment how often the axiom of stability is not satisfied for each company for each cost-sharing agreement and each allocation mechanism. Based on these results, we can make the following observations.

Table 11: Number of times the axiom of stability fails for company $i$

\begin{tabular}{c|cccc} 
Cost-sharing agreement $X_{N}$ & Game theory $(G)$ & Linear rule $(L)$ & Order rule $(\eta)$ & Square rule $(S)$ \\
\hline No cost sharing & {$\left[\begin{array}{ll}0 & 0\end{array}\right]$} & {$\left[\begin{array}{ll}0 & 0\end{array}\right]$} & {$\left[\begin{array}{ll}0 & 0\end{array}\right]$} & {$\left[\begin{array}{ll}0 & 0\end{array}\right]$} \\
Major transportation costs & {$\left[\begin{array}{ll}0 & 0\end{array}\right]$} & {$\left[\begin{array}{ll}7 & 0\end{array}\right]$} & {$\left[\begin{array}{ll}1 & 67\end{array}\right]$} & {$\left[\begin{array}{ll}1 & 67\end{array}\right]$} \\
Total transportation costs & {$\left[\begin{array}{ll}1 & 1\end{array}\right]$} & {$\left[\begin{array}{ll}8 & 2\end{array}\right]$} & {$\left[\begin{array}{lll}226 & 749\end{array}\right]$} & {$\left[\begin{array}{ll}124 & 694\end{array}\right]$} \\
Total logistics costs & {$\left[\begin{array}{ll}0 & 0\end{array}\right]$} & {$\left[\begin{array}{ll}0 & 0\end{array}\right]$} & {$\left[\begin{array}{lll}277 & 1041\end{array}\right]$} & {$\left[\begin{array}{lll}160 & 1029\end{array}\right]$}
\end{tabular}

First, we observe that when no costs are redistributed, the axiom of stability is always satisfied: under collaboration, each company will always reduce its costs compared to the stand-alone model, even when no costs are redistributed. This result is interesting, as it represents the "easiest" type of agreement. It could be argued whether this type of agreement is considered to be fair to both participating companies, as it means that you never have 
to pay for joining the vehicle of your coalition partner, but it clearly does lead to a stable collaboration where each company wins.

Second, as more costs are shared, the stability (and thus the success) of the collaboration is very sensitive to the allocation mechanism. The game theoretic gain-sharing approaches clearly dominate, yet they are not perfect. In our experiment we find that the collaboration is not stable in two instances (one per company) when the gains in the total transportation costs are shared. In those cases, the increase in inventory holding costs for an individual company outweigh its gains in total transportation costs.

The Linear rule always satisfies the axiom of stability when the total logistics costs are shared. In that case, a core allocation is stable, and the Linear rule leads to a stable collaboration. However, when only the transportation costs are shared, the Linear rule still performs very well, but it does not always lead to a win-win situation for both companies. After allocation, there are some instances where the companies perceive a gain in transportation costs, but they incur losses due to increased inventory holding costs, which are larger than the savings in transportation costs.

Finally, the Order rule and the Square rule fail to be stable in many instances when the major transportation costs, the total transportation costs, or the total logistics costs are shared. In general, we found that as the value of $K$ increases, the axiom of stability is more likely to be satisfied under these rules.

\section{Conclusions}

In current supply chain networks, transport makes up for a large part of the total logistics costs. Next to a financial impact, transport also gives rise to significant external costs for the environment and for society (e.g., increased carbon emissions, more traffic, etc.). To reduce both financial and environmental costs, companies today face huge pressure to increase their transport efficiency. After optimizing internally, companies now look for opportunities beyond their own walls, by setting up partnerships with other companies for instance. By bundling shipments with other partners, available space in vehicles used for one company can be used to transport shipments for other companies.

In this article, we studied the setting where two companies set up a collaborative shipping agreement to share the same transport vehicle. The shipments are synchronized by jointly replenishing inventories using the can-order policy. We have assessed how this synchronization impacts transportation and inventory holding costs, both at the level of the coalition as well as for each company individually. The individual cost performance under the can-order policy was evaluated using a Markov chain approach. The parameters of the can-order policy 
of both companies were optimized to minimize the total joint costs of both companies.

We find that collaboration always leads to a reduction in each company's major transportation costs, but also to an increase in their minor transportation costs. This flexibility may also require companies to keep higher inventories. However, we find that when a company experiences losses in inventories (resp. transport), the gains in transport (resp. inventories) will always outweigh these losses (it also means that a company never experiences losses in inventory and transportation costs simultaneously). In other words, each company always improves its cost performance under collaboration, even where there is no redistribution of the costs.

When the joint costs are redistributed, we can make use of cooperative game theoretic approaches (allocating half of the collaboration gains to each company) or proportional cost-allocation rules (which partition the joint cost under the collaboration based on a given indicator). When only the joint major transportation costs are shared, the Linear rule (allocating the joint costs proportionally to its respective stand-alone costs) leads more often to a stable collaboration than the Order rule (which allocates the joint costs proportionally to the squared number of orders placed in the stand-alone model). However, stability is not always guaranteed. The same holds when the total (minor and major) transportation costs are shared. This means that it may occur that after redistribution of the joint transportation costs, a company perceives gains in its transportation costs, but the collaboration increases its inventory holdings, which may even outweigh its transportation gains.

When all joint logistics costs are shared (i.e., both transportation and inventory costs), the Linear rule always leads to a stable coordination, but the Order and Square rule (allocating the joint costs based on the ratio of its respective squared stand-alone costs) often do not. The game theoretic gain sharing approaches (allocating half of the gains to each company) almost always lead to a stable solution, regardless of which costs are shared (we only found two instances where stability was not met when the total transportation costs were shared).

We conclude that, before redistribution, the total logistics costs of each company under collaboration are always smaller than (or equal to) those of the stand-alone setting. After redistribution, however, it is possible that the shipping agreement does not lead to a win-win situation because an improper choice was made with respect to the redistribution mechanism and/or the set of costs to redistribute. In this research, we have not only shown that these choices are of extreme importance, but we have also shown under which conditions a particular choice has to be made in order to ensure a stable shipping agreement.

As our findings strongly depend on the use of the can-order policy to synchronize orders, future research directions could focus on the use of other joint replenishment policies, like for instance the periodic $(s, S)$ policy (Viswanathan, 1997). Another avenue for future research 
is the investigation of the impact of information distortion on the stability of the collaborative shipping agreement. Companies may have an incentive to misreport their true parameters when simple allocation rules are employed, which may reduce the benefit from or even prohibit information sharing in supply chains. These non-obvious model extensions are full research projects themselves.

\section{References}

Anily, S. and Haviv, M., 2007. The cost allocation problem for the first order interaction joint replenishment model. Operations Research, 55(2):292-302.

Aumann, R. J. and Maschler, M., 1985. Game theoretic analysis of a bankruptcy problem from the talmud. Journal of Economic Theory, 36(2):195-213.

Balintfy, J. L., 1964. On a basic class of multi-item inventory problems. Management Science, 10(2):287-297.

Cruijssen, F., Cools, M., and Dullaert, W., 2007a. Horizontal cooperation in logistics: opportunities and impediments. Transportation Research Part E: Logistics and Transportation Review, 43(2):129-142.

Cruijssen, F., Dullaert, W., and Fleuren, H., 2007b. Horizontal cooperation in transport and logistics: a literature review. Transportation Journal, 46(3):22-39.

Doherty, S. and Hoyle, S. Supply chain decarbonisation: The role of logistics and transport in reducing supply chain carbon emissions. Logistics and transport partnership programme, World Economic Forum, Geneva, Switzerland, January 2009.

Drechsel, J. and Kimms, A., 2011. Cooperative lot sizing with transshipments and scarce capacities: solutions and fair cost allocations. International Journal of Production Research, 49(9):2643-2668.

Dror, M. and Hartman, B. C., 2007. Shipment consolidation: who pays for it and how much? Management Science, 53(1):78-87.

Dror, M., Hartman, B. C., and Chang, W., 2012. The cost allocation issue in joint replenishment. International Journal of Production Economics, 135(1):242-254.

Federgruen, A. and Zheng, Y. S., 1992. The joint replenishment problem with general joint cost structures. Operations Research, 40(2):384-403. 
Federgruen, A., Groenevelt, H., and Tijms, H. C., 1984. Coordinated replenishments in a multi-item inventory system with compound poisson demands. Management Science, 30 $(3): 344-357$.

Fiestras-Janeiro, M. G., García-Jurado, I., Meca, A., and Mosquera, M. A., 2011. Cooperative game theory and inventory management. European Journal of Operational Research, 210(3):459-466.

Frisk, M., Göthe-Lundgren, M., Jörnsten, K., and Rönnqvist, M., 2010. Cost allocation in collaborative forest transportation. European Journal of Operational Research, 205(2): $448-458$.

Gerchak, Y. and Gupta, D., 1991. On apportioning costs to customers in centralized continuous review inventory systems. Journal of Operations Management, 10(4):546-551.

Goyal, S. K. and Gupta, Y. P., 1989. Integrated inventory models: the buyer-vendor coordination. European Journal of Operational Research, 41(3):261-269.

Goyal, S. K. and Satir, A. T., 1989. Joint replenishment inventory control: deterministic and stochastic models. European Journal of Operational Research, 38(1):2-13.

Guajardo, M. and Rönnqvist, M., 2016. A review on cost allocation methods in collaborative transportation. International Transactions in Operational Research, 23(3):371-392.

Gupta, R. and Makowski, C. 2016. Facilitating Horizontal Collaboration in Supply Chains. PhD thesis, Research report zlc-2016-6, MIT Global Scale Network.

Ignall, E., 1969. Optimal continuous review policies for two product inventory systems with joint setup costs. Management Science, 15(5):278-283.

Kayiş, E., Bilgiç, T., and Karabulut, D., 2008. A note on the can-order policy for the two-item stochastic joint-replenishment problem. IIE Transactions, 40(1):84-92.

Khouja, M. and Goyal, S., 2008. A review of the joint replenishment problem literature: 1989-2005. European Journal of Operational Research, 186(1):1-16.

Körpeoğlu, E., Şen, A., and Güler, K., 2012. A private contributions game for joint replenishment. Mathematical Methods of Operations Research, 75(1):67-82.

Liu, P., Wu, Y., Xu, N., et al., 2010. Allocating collaborative profit in less-than-truckload carrier alliance. Journal of Service Science and Management, 3(1):143-149. 
Meca, A., García-Jurado, I., and Borm, P., 2003. Cooperation and competition in inventory games. Mathematical Methods of Operations Research, 57(3):481-493.

Meca, A., Timmer, J., Garcia-Jurado, I., and Borm, P., 2004. Inventory games. European Journal of Operational Research, 156(1):127-139.

Moriarity, S., 1975. Another approach to allocating joint costs. The Accounting Review, 50 (4):791-795.

Nash, J. F., 1950. The bargaining problem. Econometrica, 18(2):155-162.

Saenz, M. J., 2012. Driving more efficient logistics networks through horizontal collaboration. Supply Chain Management Review, (October 24. http: //www.scmr.com/article/driving_more_efficient_logistics_networks_through_ horizontal_collaboration/).

Schultz, H. and Johansen, S. G., 1999. Can-order policies for coordinated inventory replenishment with erlang distributed times between ordering. European Journal of Operational Research, 113(1):30-41.

Shapley, L. 1953, A values for n-person games. In Kuhn, H. and Tucker, A., editors, Contributions to the Theory of Games. Annals of Mathematical Studies 28 (vol. II, pp. 30\%-317). Princeton University Press.

Silver, E. A., 1965. Letter to the editor. some characteristics of a special joint-order inventory model. Operations Research, 13(2):319-322.

Silver, E. A., 1974. A control system for coordinated inventory replenishment. International Journal of Production Research, 12(6):647-671.

Silver, E. A., 1981. Establishing reorder points in the (S,c,s) coordinated control system under compound poisson demand. The International Journal of Production Research, 19 (6):743-750.

Thompstone, R. M. and Silver, E. A., 1975. A coordinated inventory control system for compound poisson demand and zero lead time. The International Journal Of Production Research, 13(6):581-602.

Tijms, H. C., 2003, A first course in stochastic models. John Wiley and Sons. 
Timmer, J., Chessa, M., and Boucherie, R. J., 2013. Cooperation and game-theoretic cost allocation in stochastic inventory models with continuous review. European Journal of Operational Research, 231(3):567-576.

van Eijs, M. J. G., 1994. On the determination of the control parameters of the optimal can-order policy. Zeitschrift für Operations Research, 39(3):289-304.

Vanovermeire, C. 2014. Horizontal collaboration in logistics Increasing efficiency through flexibility, gain sharing and collaborative planning. PhD thesis, University of Antwerpen, Belgium.

Vanovermeire, C., Sörensen, K., Van Breedam, A., Vannieuwenhuyse, B., and Verstrepen, S., 2014. Horizontal logistics collaboration: decreasing costs through flexibility and an adequate cost allocation strategy. International Journal of Logistics: Research and Applications, 17(4):339-355.

Viswanathan, S., 1997. Note. periodic review (s, S) policies for joint replenishment inventory systems. Management Science, 43(10):1447-1454.

Zhang, J., 2009. Cost allocation for joint replenishment models. Operations Research, 57(1): $146-156$. 